\title{
ESCOLHA PROFISSIONAL NA ADOLESCÊNCIA: UM ESTUDO PSICANALÍTICO
}

\author{
Professional Choice In Adolescence: A Psychoanalytic Study
}

Elección Profesional En La Adolescencia: Un Estudio Psicoanalítico

Choix Professionnel À L'adolescence: Une Étude Psychanalytique

DOI: $10.5020 / 23590777 . r s . v 17 i 3.5924$

\section{Juvaneide Régia Costa (Lattes)}

Psicóloga do Serviço de Psicologia Aplicada da Universidade Federal do Rio Grande do Norte (UFRN). Mestre em Psicologia pela UFRN.

\section{Cynthia Pereira de Medeiros (Lattes)}

Professora Associada do Departamento de Psicologia da UFRN. Doutora em Psicologia pela Universidade de São Paulo. Membro do GT ANPEPP Psicanálise, Infância e Educação.

\section{Cynara Teixeira Ribeiro (Lattes)}

Professora Adjunta do Centro de Educação da UFRN. Doutora em Psicologia pela Universidade Federal da Bahia. Membro do GT ANPEPP Psicanálise, política e clínica.

\section{Resumo}

As profundas transformações de ordem política, econômica e social nas sociedades capitalistas e globalizadas, geradas pelos avanços da ciência, da indústria eletrônica, da informática e da robótica, refletem-se na coletividade e nos modos de organização do mundo do trabalho. Adolescentes e jovens são afetados por essas transformações, apresentando manifestações psíquicas diversas frente à escolha de suas profissões, que denunciam o mal-estar e o sofrimento vivenciado diante das vicissitudes desse processo e das expectativas por ele geradas. Trata-se de um artigo teórico no qual articulamos as dificuldades e os impasses que envolvem a escolha profissional na adolescência às determinações psíquicas inconscientes desse processo e aos lutos que o adolescente precisará fazer para poder optar por uma profissão. A partir do referencial freudiano e lacaniano, realizou-se um estudo do conceito de adolescência que, articulado ao processo de escolha profissional e a fragmentos de casos clínicos, evidenciou as seguintes conclusões: 1. Nas escolhas humanas estão implicados processos psíquicos diversos, que, iniciados na infância, são atualizados na adolescência, determinando as escolhas do adolescente, inclusive a profissional; 2. É necessária a elaboração simbólica da separação dos pais da infância, e dos lutos relativos às perdas e renúncias relacionadas às mudanças corporais e aos objetos infantis, para que o adolescente possa aceder ao seu desejo e sustentar suas possibilidades de escolha; 3. A escuta da dimensão inconsciente, presente nas escolhas do sujeito no campo profissional, é fundamental para uma análise das dificuldades aí surgidas, bem como para o encontro de saídas singulares para elas.

Palavras-chave: identificações, adolescente, escolha profissional, Freud, Lacan.

\section{Abstract}

The profound transformation of political, economical and social order in capitalist and globalized societies generated by advances in science, electronics, computer and robotic industries are reflected in the collectivity and modes of organization of the world of work. Adolescents and young people are affected by these changes, presenting various psychical manifestations forward to choosing their professions, denouncing the malaise and suffering being experienced by them on the unpredictable change of the process and the expectations generated by it. This is a theoretical paper in which we articulate the difficulties and dilemmas that involve the professional choice in adolescence to unconscious psychic determinations of this process and the grief that the adolescent will need to do in order to 
be able to opt for a profession. From the Freudian and Lacanian framework, we performed a study of the concept of adolescence that articulated at the professional choice and fragments of clinical cases revealed the following conclusions: 1. In human choices are involved many psychological processes that started in childhood, in adolescence are updated, determining the choices of the adolescents, including their Professional ones; 2. The symbolic elaboration of separation from parents in childhood, and the grief related to loss and waivers related to bodily changes and infant objects, so that the adolescent can access their desire and support their possibility of choice; 3. Listening to the unconscious dimension present in the subject's choices in the professional field is essential to an analysis of the difficulties that have arisen therein to meet individual outputs to the same.

Keywords: identifications, teenager, professional choice, Freud, Lacan.

\section{Resumen}

Las profundas transformacións de la orden política, económica y social en las sociedades capitalistas y globalizadas generadas por los avances en la ciencia, en la industria de la electrónica, en la informática y en la robótica se reflejan en la colectividad y en los modos de organización del mundo del trabajo. Los adolescentes y los jóvenes se ven afectados por estos cambios, con la presentación de diversas manifestaciones psíquicas adelante de la elección de su profesión, denunciando el malestar y el sufrimiento que se vive, las vicisitudes del proceso y las expectativas generadas por el mismo. Se trata de un trabajo teórico en el que articulamos las dificultades y dilemas que implican la elección profesional en la adolescencia a las determinaciones psíquicas inconscientes de este proceso y a la pena que el adolescente tendrá que hacer para ser capaz de elegir una profesión. Desde el marco freudiano y lacaniano, se realizó un estudio sobre el concepto de adolescência que, en articulacion a la elección profesional y a fragmentos de los casos clínicos, reveló las siguientes conclusiones: 1. En las elecciones humanas están involucrados muchos procesos psicológicos que comenzaron en la infancia, se actualizan en la adolescencia, determinando las opciones de los adolescentes, incluida la profesional; 2. Se requiere la elaboración simbólica de la separación de los padres en la infancia, y el dolor relacionado con la pérdida y exenciones relacionadas con los cambios corporales y objetos infantiles, por lo que el adolescente puede acceder a su deseo y apoyar su elección; 3. Escuchar a la dimensión inconsciente presente en las elecciones del sujeto en el campo profesional es esencial para una análisis de las dificultades vividas en el mismo y para encontrar salidas individuales a las mismas.

Palabras clave: identificaciones, adolescente, elección profesional, Freud, Lacan

\section{Résumé}

La transformation profonde de l'ordre politique, économique et sociale dans les sociétés capitalistes et mondialisés générés par les progrès de la science, de l'industrie de l'électronique, de l'informatique et de la robotique se reflète dans la collectivité et des modes d'organisation du monde du travail. Les adolescents et les jeunes sont touchés par ces changements, présentant diverses manifestations psychiques avant de choisir leur profession, dénoncer le malaise et la souffrance vécue par eux, les vicissitudes du processus et les attentes générées par celle-ci. Il s'agit d'un article théorique dans lequel nous articulons les difficultés et les dilemmes qui impliquent le choix professionnel de l'adolescence à des déterminations psychiques inconscients de ce processus et la douleur que votre enfant aura besoin de faire pour être en mesure de choisir une profession. Du cadre freudien et lacanien, nous avons effectué une étude de la notion de l'adolescence que, que articulé a le choix professionnel et les fragments de cas cliniques révélé les conclusions suivantes: 1. Dans les choix humains sont impliqués processus psychologiques qui ont commencé dans l'enfance, à l'adolescence sont mis à jour, déterminer des choix des adolescents, y compris professionnelle; 2. C'est nécessaire l'élaboration symbolique de séparation des parents dans l'enfance, et la douleur liée à la perte et des dérogations des changements corporels et des objets infantiles, de sorte que l'adolescent peut accéder à votre désir et soutenir leur choix; 3. Écouter la dimension inconsciente présente dans les choix du sujet dans le domaine professionnel est essentiel à l'analyse des difficultés à l'intérieur et à répondre à des sorties individuelles de la même rencontrés.

Mots-clés: identificacion, adolescent, choix professionnel, Freud, Lacan.

Nas últimas décadas, com os avanços da ciência, da indústria eletrônica, da informática e da robótica, as sociedades capitalistas e globalizadas têm passado por profundas transformações de ordem política, econômica e social, que se refletem na coletividade e, consequentemente, nos modos de organização do mundo do trabalho.

Adolescentes e jovens, também afetados por essas transformações, apresentam, como consequência, manifestações psíquicas diversas frente à escolha de suas profissões (dúvidas, indecisão, paralisação diante da escolha de um curso de 
graduação, etc.), as quais denunciam os impasses e sofrimentos que vivenciam perante as vicissitudes desse processo e das expectativas por ele geradas.

As referidas manifestações psíquicas e as queixas que delas decorrem também se tornaram presentes na escuta clínica de adolescentes e jovens atendidos no Serviço de Psicologia Aplicada (SEPA) da Universidade Federal do Rio Grande do Norte, levando-nos a algumas indagações acerca da complexa trama de construções psíquicas inconscientes que estariam implicadas nas dificuldades apresentadas nesse processo, por vezes difícil para alguns, da escolha profissional.

Neste artigo, faremos, então, algumas articulações entre as dificuldades e impasses que envolvem essa escolha na adolescência e as determinações psíquicas inconscientes a ela subjacentes, que, constatadas como presentes na prática clínica, também se confirmaram como importantes na literatura acerca do assunto.

A partir do referencial freudiano e lacaniano, realizaremos, inicialmente, um estudo do conceito psicanalítico de adolescência, objetivando, sobretudo, apontá-la como um conjunto de operações psíquicas, dentre as quais a escolha profissional é uma das mais importantes. Em seguida, traremos fragmentos de casos clínicos, a fim de articularmos essa escolha às suas determinações inconscientes e à elaboração dos lutos vivenciados pelo adolescente no decorrer dessas operações. Por fim, apresentaremos nossas conclusões, apontando a importância de lançarmos um novo olhar sobre essa escolha e para as formas de escuta das dificuldades aí envolvidas.

\section{Construção do Conceito de Adolescência na Psicanálise}

Abordada pelos diversos campos das ciências humanas e biológicas (Psicologia, Filosofia, Antropologia, Sociologia e Fisiologia) como uma etapa cronológica do desenvolvimento biopsicossocial do ser humano, cuja passagem o expõe a crises e/ou manifestações patológicas (Poli \& Becker, 2004), o conceito de adolescência será aqui apresentado pelo prisma da Psicanálise. Nessa perspectiva, abordaremos tal conceito a partir das repercussões psíquicas geradas pelo confronto do adolescente com questões estruturais importantes relativas à sua sexualidade e inserção em laços sociais que se estendem para além do âmbito familiar.

Considerando, pois, que o conceito psicanalítico de adolescência encontra seu suporte na construção histórica da humanidade, acreditamos ser necessário, antes de abordarmos seus desdobramentos na Psicanálise freudiana e lacaniana, realizarmos um breve percurso acerca da sua construção histórico-social.

O termo adolescência é de origem latina (vem de adulescens ou adolescens, particípio passado do verbo adolescere) e é composto pelos prefixos $a d$-, que significa "para frente", mais dolescere, que significa "crescer com dores" (Costa, 2007), denotando tratar-se de uma passagem incontornável da vida humana que não pode ser feita sem algum sofrimento.

A sua origem na sociedade moderna ocidental, segundo alguns historiadores, deu-se no final do século XVIII, tendo alcançado maior expressão em meados do século XIX, quando o mundo infantil e o mundo adulto passaram a ser vistos como espaços distintos (Ariès, 1981).

Para Coutinho (2009), apesar de ter alcançado maior expressividade no meio social no século XIX, foi no século XX que a noção de adolescência tomou a forma que tem na atualidade, tornando-se um período específico da vida humana. Nesse século, segundo ela, o interesse pela adolescência voltou-se, sobretudo, para a "adoção de posturas ambivalentes em relação a essa etapa da vida - por um lado, um certo fascínio; por outro, a necessidade de controle" (p. 137). Para a referida autora, foi pela ótica da necessidade de controle que, nesse momento, foram realizadas várias publicações no campo da Psicologia, da Educação e da Psicanálise. Como exemplos dessas publicações, cita os livros: Adolescência, de Stanley Hall, publicado em 1904; os Três ensaios sobre a sexualidade infantil, de Freud, publicado em 1905; e a revista L'Education, publicada em 1919.

De acordo com Coutinho (2009), esses três campos de saber não só contribuíram para definir como também para divulgar a noção de adolescência. A Psicanálise contribuiu, sobretudo, para a consolidação desse conceito, nas décadas de 1970 e 1980, por meio das produções de Erickson e de suas teorias em torno da noção de adolescência como "moratória social", e de Aberastury e Knobel, com as suas concepções da "adolescência normal e patológica". A partir daí, ficou estabelecido o conceito de adolescência como uma etapa natural do desenvolvimento humano, "definida sempre através de uma visão normatizante e atenta ao caráter semi-patológico que apresentava" (Coutinho, 2009, p. 138).

Assumindo uma posição contrária a essa concepção evolutiva, normatizante e patologizante da adolescência, difundida pela Psicologia e por alguns teóricos da Psicanálise, Coutinho (2009) expõe uma nova concepção da adolescência, que é também compartilhada por outros autores psicanalíticos da contemporaneidade. Nesta, a adolescência é vista como um trabalho psíquico imposto ao jovem, na nossa cultura, a fim de que ele possa fazer sua passagem do laço familiar ao laço social. Para a referida autora, a nossa sociedade, diferentemente das sociedades tradicionais, as quais possuem rituais iniciáticos que auxiliam o jovem nessa passagem, não oferece direções claras que orientem os nossos adolescentes nesse percurso. 
Nesse sentido, Mannoni (1996) assinala que o modelo escolar, utilizado na nossa sociedade como uma importante forma de passagem do adolescente para a vida adulta, mostra-se complexo e contraditório, dada a falta de clareza sobre o que está em jogo no processo educacional. Para a autora, a consequência disso é que "o adolescente chega à idade adulta sem garantia quanto ao lugar que será levado a ocupar entre os mais velhos e entre seus pares" (p. 14).

Acerca desse lugar da escola na passagem do adolescente para o mundo adulto, Viola e Vorcaro (2015) assinalam que, mesmo com o declínio da autoridade da instituição escolar, esta permanece como "principal cenário para o laço social do adolescente" (p. 68), uma vez que é nela que muitos adolescentes passam um tempo considerável de suas vidas, vivenciam conflitos, encontros amorosos, fracassos e êxitos, podendo aí constituir as filiações necessárias à aquisição do saber.

Ainda sobre esse aspecto, as referidas autoras concordam com Lima (2012), que postula a impossibilidade de aquisição de um saber que não seja pelo Outro encarnado no mestre.

A partir dessas reflexões, temos elementos para defender que para alguns adolescentes a escola ainda se coloca como um lugar importante para a aquisição dos referenciais e ideais simbólicos necessários para a sua inserção no laço social. Contudo, é necessário ressaltar que na atualidade tais ideais e/ou referenciais estão majoritariamente atrelados aos modelos estabelecidos pelo mercado de trabalho e pelo sistema capitalista.

Devido às exigências desse modelo capitalista, constatamos hoje que a escolarização tem deixado de ser uma garantia de certeza em relação ao futuro; fato esse que tem levado muitos adolescentes e jovens ao adiamento de sua entrada no mundo do trabalho, em função de exigências cada vez maiores de especialização e qualificação no campo profissional. Como consequência desse adiamento, também ocorre uma prorrogação da dependência em relação aos pais, a qual tem ganhado proporções cada vez mais alarmantes na nossa sociedade.

A dependência em relação aos pais é também estendida às instituições escolares, principalmente de nível superior, nas quais se observa um número cada vez maior de jovens que prorrogam o término de seus cursos alegando a necessidade de adquirirem mais experiências de estágio e melhor capacitação para poderem enfrentar em melhores condições o mercado de trabalho competitivo e excluidor que, para eles, coloca-se como inevitável, dada a situação de crise econômica e de desemprego do mundo atual.

Calligaris (2000), ao falar dos ideais impostos pela modernidade à adolescência, afirma que o individualismo de nossa cultura tem prezado, acima de tudo, a independência e a autonomia, sendo a transmissão desses valores um dos principais objetivos da educação moderna. Tais valores, segundo o referido autor, apesar de serem transmitidos pela escola como forma de tornarem o jovem um adulto maduro, acabam por revelar uma contradição, pois a permanência na escola é o próprio adiamento da entrada na vida adulta, sendo precisamente esse adiamento que pode torná-lo inadaptado e imaturo.

O autor comenta, ainda, que o alargamento desse "tempo de suspensão ou moratória" (p. 17), concedido ao adolescente na sociedade contemporânea, acabou por afetar a própria definição temporal de adolescência. Para ele, hoje, não mais parece existir um marco para o início e término da adolescência, observando-se, pois, a existência de adultos, acima dos 40 anos, ainda em situações de vida mais comuns na juventude (fazendo faculdade e/ou cursos técnicos, mudando de profissão, etc.), bem como adotando comportamentos e atitudes característicos dos jovens (indo para baladas, usando roupas e gírias próprias dos adolescentes, etc.).

Calligaris (2000) também assinala que o jovem "não sabe quando e como vai poder sair de sua adolescência" e que a ele é imposto "o inexplicável dever de ser feliz, pois vive uma época da vida idealizada por todos" (p. 21). Esse imperativo de felicidade, impingido ao adolescente, na atualidade, leva o autor a supor que o século XX fez da adolescência um ideal cultural, por ser vista como um tempo de liberdade e felicidade irrestritas, desejado, portanto, pelos adultos, que almejam a ele retornar, e pelos próprios adolescentes, que querem nele permanecer.

Corroborando essas afirmações, Dantas (2002) comenta, com certa ironia, que a expressão usada por Freud, "Sua majestade, o bebê", para referir-se à relação narcísica da criança com os seus pais, poderia ser reescrita sob a forma "Sua majestade, o adolescente", para dar conta desse sintoma social que o adolescente se tornou ao ocupar o lugar de ideal cultural da sociedade contemporânea.

Para Coutinho (2009), o ideal cultural da adolescência, articulado à pulverização das referências simbólicas, na contemporaneidade, traz sérias consequências no que diz respeito à construção dos ideais sociais dos adolescentes. Segundo a autora, "sem pontos de ancoragem que propiciem novas identificações, torna-se mais difícil para o adolescente fixar para si próprio um ideal que lhe sirva de referência para encontrar possíveis meios de escoamento libidinal" (p. 20).

Diante dessa perspectiva de crise dos ideais culturais da nossa sociedade, de crise do próprio adolescente e também dos principais dispositivos sociais - a família e a escola -, que poderiam lhe dar a sustentação necessária para a difícil operação subjetiva de aquisição do estatuto de adulto, torna-se cada vez mais frequente entre os jovens da contemporaneidade a apresentação de manifestações psíquicas que tanto podem trilhar o caminho das patologias mais graves (bulimia, anorexia, etc.) e dos atos que põem em risco a vida (tentativas de suicídio, sexo promíscuo, esportes perigosos, etc.) ou desafiam as 
leis (adesão a drogas, direção perigosa no trânsito, etc.), como também o caminho da dúvida e da incerteza quanto ao futuro, o que leva muitos adolescentes a procurarem ajuda para suas dificuldades ligadas à escolha profissional.

Tendo, pois, em vista que as dificuldades relativas à passagem do adolescente do laço restrito da família para laços sociais mais amplos, como o mundo do trabalho, estão incluídas entre as problemáticas da atualidade que se apresentam na clínica psicanalítica com adolescentes, abordaremos, a seguir, as teorizações da Psicanálise, especialmente de Freud e Lacan, acerca do trabalho subjetivo que se opera durante essa passagem.

Sabemos que esses autores não se debruçaram com mais profundidade sobre o estudo da adolescência. No entanto, entendemos que os ensinamentos de ambos poderão nos fornecer um campo de reflexão fecundo acerca das operações psíquicas que nela ocorrem, incluindo-se entre elas as várias escolhas que o adolescente precisa fazer nos campos profissional, afetivo e social.

\section{A adolescência na perspectiva freudo-lacaniana}

Três ensaios sobre a teoria da sexualidade (Freud, 1905/1987a) e a Conferência XXI - O desenvolvimento da libido e as organizações sexuais (Freud, 1916-17/1987b) constituem-se nos principais textos freudianos que contribuem para o estudo do que, hoje, entendemos por adolescência. Em ambos, Freud raramente usou tal termo. Na maioria das vezes, referiu-se à puberdade. Tal fato tem sua justificativa no próprio contexto histórico e social de sua época, no qual a adolescência não se apresentava como um momento particular da vida nem tinha a relevância social que tem atualmente.

Três ensaios é considerado uma das obras mais importantes da teoria freudiana, pois é nesse texto que a sexualidade infantil é finalmente reconhecida, perdendo a puberdade o lugar de exclusividade das primeiras manifestações sexuais do ser humano. Nele, Freud, além de apresentar a relação mãe-bebê como uma referência para as relações posteriores do ser humano, também aponta os seguintes processos pertinentes à puberdade: 1. Conclusão da conduta sexual e configuração definitiva da sexualidade, quando se dá a organização das pulsões parciais sob o primado da genitalidade, a abertura para a escolha de objetos sexuais alheios e o posicionamento em uma das formas da vida sexual: normal, perversa ou neurótica; 2. Reorganizações e novas composições das pulsões sexuais, que, quando não realizadas, geram perturbações patológicas e 3 . Desligamento das figuras parentais e estabelecimento de laços sociais fora do âmbito familiar.

Na Conferência XXI, Freud (1916-17/1987b) retoma os pontos levantados em Três ensaios, discorrendo, novamente, sobre o processo psíquico a ser realizado pelo jovem púbere ao desvincular-se dos pais para tornar-se membro da comunidade social. Segundo ele, a força libidinal reativa as escolhas objetais infantis, ocorrendo, então, uma "revivescência do complexo de Édipo". O trabalho do jovem, nesse momento, será, sobretudo, o de recalcar, pela segunda vez, as premissas trazidas pelo Édipo. Porém, tal trabalho raramente é realizado por completo, pois o Édipo, em muitos casos, não é superado completamente, situando-se aí o núcleo das neuroses.

Tal conclusão será retomada posteriormente, em Moisés e o Monoteísmo (1939/1987e), quando inclui um novo e importante fator capaz de desencadear a neurose na puberdade: o trabalho psíquico a ser feito pelo jovem frente aos embates do ego com as exigências do mundo externo. Tal trabalho leva o adolescente a ter de lidar, agora, com duas exigências: as libidinais, que dizem respeito ao despertar do desejo sexual e das fantasias incestuosas, e as sociais, que se referem às demandas do mundo externo. Ambas exigirão a sua separação das figuras parentais e o estabelecimento de novos laços sociais.

A teoria lacaniana, também concebendo a adolescência como um processo de reelaboração do recalque e da castração, relacionado ao retorno da vivência edípica da infância, sinaliza para duas operações psíquicas que são inerentes a esse processo e que serão detalhadas adiante: a validação da metáfora paterna ${ }^{1}$, com a consequente reinscrição do Nome-do-Pai, e o acesso a uma relação genitalizada com o Outro ${ }^{2}$ sexual. Ambas as operações se dão a partir das relações entre o imaginário, o simbólico e o real ${ }^{3}$ e de movimentos constantes de alienação e separação em relação ao Outro parental ou seus substitutos, tendo o seu início com a reedição do estádio do espelho, processo no qual se deu a formação imaginária do eu, na infância, que retorna, na adolescência, em função do encontro do sujeito adolescente com as transformações pubertárias.

Trata-se de um conceito lacaniano que diz respeito à intervenção do Nome-do-Pai, significante metafórico que, no Complexo de Édipo, atua sobre o desejo da mãe, barrando a relação mãe-filho, instaurando a lei da proibição do incesto para a criança e retirando-a do lugar de objeto central do desejo da mãe.

2 "Termo utilizado por Jacques Lacan para designar o lugar simbólico - o significante, a lei, a linguagem, o inconsciente, ou, ainda, Deus, - que determina o sujeito, ora de maneira externa a ele, ora de maneira intra-subjetiva em sua relação com o desejo" (Roudinesco \& Plon, 1998, p. 558).

3 São os três registros que, segundo a teoria lacaniana, embasam a experiência humana. O simbólico é a ordem da linguagem que contém os significantes; o imaginário opera no campo das imagens, mais especificamente da imagem corporal (narcísica) e o real diz respeito ao que não é simbolizável, ao que não pode ser pensado ou representado. 
O estádio do espelho caracteriza-se pela operação psíquica na qual o eu se constitui a partir da identificação primordial do infans com a imagem do semelhante (geralmente o Outro materno). A percepção dessa imagem antecede a própria maturação fisiológica e motora da criança, levando-a a diferenciar o seu corpo do mundo, bem como a situar o que faz e o que não parte do seu eu. A identificação com essa imagem unificada leva-a a superar o momento anterior, de corpo fragmentado, e a constituir uma espécie de matriz egóica (Lacan, 1998).

Além de ser uma operação estruturante do eu, o estádio do espelho funda um lugar para o engate do simbólico, isto é, trata-se de uma experiência na qual o eu se precipita; somente possível porque há um suporte simbólico. No jogo especular entre a criança e o semelhante (a mãe ou seu substituto) é o Outro materno (como representante do simbólico) que confere significado para a imagem que ela vê e a partir da qual se constitui.

Para continuar se constituindo, a criança precisa sair dessa relação especular, de alienação imaginária ao Outro materno, separando-se simbolicamente do mesmo. Para que essa separação ocorra, faz-se necessária a estrutura significante do Nomedo-Pai operando a castração pela articulação entre o imaginário e o simbólico. A experiência imaginária da castração, posta em ação a partir da entrada desse significante na relação da criança com o Outro materno terá, portanto, a função de fazer esse corte, estabelecendo a triangulação própria da vivência edípica.

Nessa perspectiva, o Pai (não o real, mas aquele que tem a função de representante de uma lei, a de proibição do incesto) tem um lugar de extrema importância no complexo de Édipo. A ele caberá interditar a mãe, privando-a do seu desejo de transformar o filho em seu objeto exclusivo de gozo, e também o filho, frustrando-o no seu desejo de posse exclusiva da mãe. Essa função paterna é, portanto, uma metáfora, ou seja, um significante 4 que surge no lugar daquilo que simboliza a operação da ausência da mãe. A essa operação de substituição de significantes, Lacan (1999) deu a denominação de metáfora paterna.

Segundo o referido autor, a partir dessa operação, o pai simbólico, que nesse momento intervém como portador do falo, é internalizado pela criança como ideal do eu, posição que se diferencia da anterior, de eu ideal, que a criança ocupou diante do Outro materno, por ocasião do estádio do espelho, em função dessa última comportar uma imagem de perfeição e completude que a remetia à posição de falo da mãe. Nesse sentido, a metáfora paterna desempenha exatamente o que se espera de uma metáfora: "leva à instituição de alguma coisa que é da ordem do significante, que fica guardada de reserva e cuja significação se desenvolverá mais tarde" (Lacan, 1999, p. 201), ou seja, na adolescência.

$\mathrm{Na}$ adolescência, de acordo com Lacan (1999), a operação efetuada na infância por ocasião do estádio do espelho é atualizada em função das mudanças fisiológicas e corporais impostas pelas transformações pubertárias. Nesse sentido, Backes (2011) afirma:

“(...) na adolescência temos a possibilidade de ver como o adolescente reconstitui esta operação. É como se seu corpo precisasse ser novamente contido e reescrito por significantes. Trata-se tão somente do luto pelo corpo da infância e da assunção de um 'novo' corpo adulto" (p. 32).

Rassial (1997), a partir da perspectiva lacaniana, também aponta como uma outra importante operação psíquica da adolescência o acesso a uma relação genitalizada com o Outro sexo. Segundo ele, para essa operação acontecer é necessária a ocorrência paralela de duas outras: a modificação do lugar que a criança ocupava no desejo dos pais e a revalidação da metáfora paterna, com a consequente reinscrição do Nome-do-Pai, como significante capaz de novamente barrar o incesto e promover o posicionamento do adolescente na partilha dos sexos. Para Rassial (1997), tais operações só se tornam possíveis devido à ocorrência do que ele denominou de "pane imaginária do Outro parental", que nada mais é do que a desqualificação do pai e da mãe em encarnarem imaginariamente o Outro. Tal fato ocorre, segundo ele, porque a promessa do direito e acesso a um gozo de mesmo peso e tamanho do renunciado na infância, com a chegada na adolescência, se mostra enganosa, dada a impossibilidade de completude nas relações com o Outro sexo e do reconhecimento que o objeto primordial está para sempre perdido.

Rassial (1997), pensando sobre os modos de operar com essa "pane imaginária do Outro parental", pontua que o adolescente pode substituir o laço familiar pelo laço com um grupo similar, como o exército e a igreja, protegendo-se dessa prova, ou então autorizar a si mesmo através dos vários Nomes-do-Pai ${ }^{5}$ (são exemplos destes a profissão, os esportes, as

$4 \quad$ Significante é um termo estabelecido por Ferdinand Saussure em seus estudos sobre a Linguística. Para ele, cada signo linguístico é composto pelo significante (imagem acústica) e pelo significado (conceito), que se associam entre si. Na teoria lacaniana, o significante vem antes do significado e diz respeito ao elemento do discurso consciente ou inconsciente do sujeito. Para Lacan (1998), "um significante é aquilo que representa o sujeito para outro significante" (p. 196). A transmissão dos significantes se realiza no contato-convivência com os pequenos outros (pais, parentes, professores, etc.), os quais são os representantes do grande Outro (a cultura, o social, o inconsciente).

5 Rassial (1997) faz referência aos últimos ensinos de Lacan, empreendidos na década de 70, no qual este postula a pluralização do Nome-doPai, formulando que outros elementos, incluindo o próprio Pai simbólico, poderiam ser utilizados no lugar desse significante, como meio de validação, na adolescência, da operação que o mesmo propicia, que é a reinscrição do adolescente na ordem simbólica. 
artes, etc.) oferecidos pela cultura para se nomear diante do Outro social. Nesse sentido, a profissão, como um dos Nomesdo-Pai, pode se constituir como uma das muitas formas de inscrição do adolescente no laço social.

\section{Escolha profissional e suas determinações psíquicas}

Tendo em vista a escolha da profissão ser o ato decisório que, normalmente, precede a entrada do sujeito em alguma forma de preparação para o exercício posterior de um trabalho, ofício e/ou ocupação, torna-se importante que, antes de falarmos dela, teçamos algumas breves considerações acerca do trabalho, não somente por sua importância na formação da sociedade, mas, principalmente, por seu caráter de mediador entre o mundo interno (subjetivo) e o mundo externo (a realidade social) do ser humano (Torres, 2001).

Freud (1930/1987d), em O Mal-estar na Civilização, relacionando o trabalho a uma condição psíquica de neurose ou de normalidade do indivíduo, ressaltou a sua importância como forma de inseri-lo na realidade social:

Nenhuma outra técnica para a conduta da vida prende o indivíduo tão firmemente à realidade quanto a ênfase concedida ao trabalho, pois este, pelo menos, fornece-lhe um lugar seguro numa parte da realidade, na comunidade humana (p. 99)

Para Freud, o trabalho, além de meio de prender o homem à realidade, é também fonte de investimento libidinal, pois lhe oferece a possibilidade de deslocar uma grande quantidade de componentes libidinais, sejam eles narcísicos, agressivos ou mesmo eróticos.

Torres (1998) aborda duas dificuldades fundamentais para o processo de escolha profissional: de um lado, as transformações atuais no mundo do trabalho e, de outro, o momento em que ela comumente se dá, a adolescência, "onde são frequentes os conflitos, as dúvidas, as ansiedades, os medos, o desconhecimento e a falta de preparação para enfrentar as questões que certamente irão apresentar-se no curso da vida" (p. 12).

Para a referida autora, o processo de opção por uma profissão começa a ser construído no tempo de estruturação do psiquismo e envolve as relações do sujeito com as noções psicanalíticas de escolha de objeto, sobredeterminação e identificações, todas elas essenciais à constituição da subjetividade.

Segundo Torres (1998), é a partir das relações estabelecidas com os primeiros objetos amorosos que o sujeito aprende a relacionar-se com os demais objetos de sua vida, sendo essa experiência infantil a responsável, em grande parte, pelos aspectos afetivos e sensuais dos objetos que receberão investimentos na idade adulta. Nesse sentido, o conceito de objeto pode ser associado ao processo de escolha profissional a partir do momento em que se pode conceber a profissão eleita, pelo sujeito, como um objeto que integra investimentos de ordem energética, pulsional, intelectual, afetiva, etc. Segundo essa autora, é por ter uma estrutura psíquica advinda de uma vida submetida à linguagem, aos processos identificatórios e às relações com o mundo que o adolescente aprende a lidar com os vários tipos de objetos que lhe são apresentados, inclusive os diferentes ramos ocupacionais determinados socialmente, e pode, assim, fazer suas escolhas (Torres, 2001).

Nessa perspectiva, a autora afirma que a escolha não diz respeito a opções racionais entre duas ou mais coisas, mas ao sentido de irreversibilidade e determinação inconsciente com que o sujeito elege seu tipo de amor objetal em um determinado momento da vida infantil. A mesma ressalta que o investimento feito nos objetos de amor da infância servirá de protótipo para os demais investimentos objetais que o sujeito fará no decorrer de sua vida, inclusive no âmbito profissional.

Já o conceito de sobredeterminação referenda a ideia de quanto um processo de escolha profissional é complexo, envolvendo múltiplas determinações e elementos de diversas ordens: as construções psíquicas conscientes e inconscientes; as interferências dos modelos de adultos (familiares ou outros), através dos processos identificatórios; as aprendizagens alcançadas durante a vida cultural; as experiências interpessoais e intrapessoais, vivenciadas e acumuladas; a maneira como a pessoa aprendeu a fazer seus investimentos objetais na infância; a situação profissional e mercadológica vigente; a realidade social em geral, etc.

Alberti (2010), fazendo uso da teoria lacaniana, também aponta para as múltiplas determinações dessa escolha e para as limitações do sujeito frente a elas:

Múltiplas causalidades e conjunturas se propõem, não sempre as mesmas de um sujeito para outro: elas podem estar mais ou menos na sua história, na determinação inconsciente e significante, ou podem estar mais referidas a uma forma de gozar, ou ainda a uma conjuntura particular do laço social no qual o adolescente esteja inserido. Tudo isso já limita enormemente o campo de cada sujeito. (p. 39)

A referida autora segue afirmando que a escolha profissional, por implicar sempre em um ponto de basta, além de não oferecer muitas possibilidades ao sujeito adolescente, também se coloca como insistência de uma determinação que lhe é 
própria. Para a mesma, dadas as causas e conjunturas que interferem nessa escolha, é necessário que "a pergunta 'Quem sou eu?', surgida da própria vacilação das identificações na adolescência, já não cause tanta angústia. É inevitável que o adolescente possa tê-la respondido de alguma maneira a partir do que faz, mesmo que seja impossível respondê-la toda" (p. 40).

Com relação à identificação, Torres (2001) assinala ser esse processo extremamente relevante para o surgimento do sujeito humano. A autora ressalta que a identificação é caracterizada por Freud (1921/1987c) como a mais remota expressão de um laço emocional com outra pessoa, laço este que, em nossa cultura, normalmente, ocorre primeiro com as figuras parentais.

Para Freud (1921/1987c), é na passagem pelo Édipo, sobretudo, que a criança se apropria de traços característicos de seus objetos parentais, que passam a se constituir como modelos ou ideais internalizados. Ao brincar, imitar e jogar com as possibilidades que esses modelos oferecem, a mesma vai formulando, gradativamente, conceitos e/ou representações sobre si e as coisas do seu mundo social.

Esse processo, iniciado com as figuras parentais, estende-se, posteriormente, às relações com as figuras próximas, com as quais a criança convive ou conviverá, tais como: professores, amigos, parentes, entre outros; e também com figuras idealizadas, como heróis, artistas, esportistas, etc., que servirão de modelos constitutivos das identificações do sujeito, não só no que diz respeito à sua sexuação, como também à sua inserção social e ocupacional futura.

No que tange à questão profissional, vemos que, desde muito cedo, a criança ouve os adultos falando sobre "trabalho" e, precocemente, captura o sentido deste para as figuras identificatórias significativas. Os comentários, as ações e o próprio desempenho das atividades profissionais pelo adulto imprimem as bases da internalização desse significante para a criança, sendo, então, dessa forma que ela vai gradativamente conferindo-lhe significado.

As marcas da cultura, que orientam o modo de organização familiar e a constituição psíquica, são elementos significativos para a definição das identificações do sujeito. Na nossa sociedade, a família e a escola constituem-se como lugares privilegiados para a formação das referências a serem seguidas, influenciando na escolha profissional e/ou na estruturação de um projeto de carreira (Bohoslavsky, 1993). Assim, apesar de os modelos profissionais transmitidos por essas instâncias não serem necessariamente seguidos, é a partir delas que cada um introjeta as referências identificatórias relativas à escolha da profissão.

Ampliando as análises acerca dessa influência nas escolhas do sujeito, Alberti, (2010) afirma:

Não há escolha que prescinda de indicativos, direções, determinantes que lhe são anteriores. O sujeito os recebe ao longo de sua infância, dos pais, educadores, colegas, meios de comunicação, enfim, do mundo a sua volta, através do que lhe é transmitido pela linguagem falada, escrita, visual, comunicativa ou ainda pelo silêncio. E pode continuar recebendo esses mesmos indicativos, direções e determinantes, ao longo de todo processo adolescente, desde que não falte quem lhe possa transmiti-los. (p. 10)

Apresentadas as operações psíquicas da adolescência mais comumente estudadas pela Psicanálise e as determinações inconscientes a que o adolescente está submetido ao escolher sua profissão, discutimos, a seguir, as articulações de tais operações com esse processo.

\section{Articulações entre as Operações Psíquicas da Adolescência e o Processo de Escolha Profissional}

Segundo Alberti (2010), o trabalho psíquico da adolescência se inscreve na difícil e necessária elaboração do binômio alienação-separação em relação ao Outro parental. No plano da escolha profissional, vemos que esse trabalho de elaboração do binômio alienação-separação leva o adolescente a ter que fazer uma série de lutos pelas perdas e renúncias que precisarão acontecer para que ele possa optar por uma profissão.

Bohoslavsky (1993) acrescenta ainda que, na adolescência, o sujeito se depara com a necessidade de elaborar vários lutos. Ao entrar na puberdade, há o luto pelos pais da infância, pelo corpo infantil, pela onipotência perdida, etc. A estes, somam-se o luto pelas escolhas profissionais da infância, pelos antigos projetos, pelas renúncias feitas, dentre outros.

A elaboração desses lutos concernentes à adolescência é uma das mais importantes operações psíquicas a ser viabilizada pelo adolescente. Para analisar especificamente cinco lutos fortemente relacionados ao momento de escolha profissional, traremos alguns fragmentos de casos retirados tanto da prática clínica das autoras no Serviço de Psicologia da UFRN, como também da prática clínica de autores citados neste artigo.

O primeiro desses lutos diz respeito à perda das escolhas profissionais da infância. Sobre essas escolhas, Levenfus (1997) afirma que elas, possivelmente, serão substituídas a partir do confronto do adolescente com o mundo real. Tal confronto lhe evoca sentimentos de perda relativos às facilidades com que, nas suas brincadeiras da infância, podia escolher ser qualquer profissional e por perceber, agora, a complexidade dessa escolha, que envolve conjunturas e determinações diversas. 
Segundo a autora, o luto pelas escolhas profissionais da infância "propõe uma transformação na qual muito do prazer deve ser retido, porque agora a satisfação é buscada com maior respeito pelas exigências da realidade" (p. 164). Assim, a elaboração desse luto sempre deixa restos que retornam posteriormente, seja na atividade de trabalho da vida adulta, seja nas dificuldades em relação a esta.

Para Rodulfo (1990), o desejo implicado no brincar infantil e adolescente cede grande parte de sua força e poder para a atividade laboral, a qual é central na vida adulta. Essa transposição é necessária para que o trabalho possa advir investido de uma base pulsional decisiva sem a qual "não pode se constituir, ou se pseudo constitui, como uma fachada talvez socialmente muito produtiva, mas subjetivamente vazia de significação" (p. 158).

O referido autor segue afirmando que, na transposição do brincar infantil para a atividade de trabalho adulta, surgem inúmeras dificuldades, as quais indicam certa insistência dos objetos pulsionais da infância e uma aderência do sujeito adolescente ou adulto a esses objetos.

Como exemplo disso, tomamos por empréstimo a história de um adolescente de nome Lucas, cujo caso foi discutido por Backes (2011), que fazia um estágio voluntário do curso superior de Fisioterapia, enquanto recebia de seus familiares uma mesada que lhe garantia o sustento de suas necessidades básicas. Assim, o estágio ficava no lugar do trabalho profissional e remunerado que ele não conseguia constituir. Mantendo-se atarefado numa atividade que era quase "uma brincadeira", Lucas furtava-se de entrar em contato com a angústia que envolvia a construção de um projeto profissional que lhe proporcionasse independência financeira.

Para a referida autora, o caso de Lucas oferece elementos que apontam para o "fracasso dessa metamorfose do brincar em trabalhar, que impede o investimento no campo profissional, pois a atividade lúdica acaba prevalecendo e impedindo o deslocamento de um quantum libidinal de um campo a outro" (p. 92).

Nesse sentido, Rodulfo (1990) assinala que a atividade de trabalho vai exigir do sujeito que ele possa não somente superar a onipotência infantil, mas também "passar suas qualidades por um certo código e aceitar entrar em contato com procedimentos e saberes já instituídos” (p .170). É, portanto, pela aceitação das regras instituídas pelo Outro que o adolescente poderá transformar a atividade lúdica da infância na atividade de trabalho da vida adulta.

Bohoslavsky (1993), também associando as dificuldades decorrentes do luto das escolhas da infância com as dificuldades de elaboração da onipotência infantil, afirma que, quando esta última é negada, surge no adolescente a fantasia de seguir "carreiras monstros", as quais supõem a negação dos próprios limites e a incapacidade do jovem em renunciar a antigos projetos para adequar-se à realidade. É o que nos aponta o seguinte relato:

'Vou primeiro estudar Física e Astronomia, para entender como o universo está organizado; depois Biologia, Veterinária e Medicina, para entender os fenômenos vivos da realidade, tanto nos animais como nos seres humanos; depois Filosofia, para dar um sentido a tudo isso, e Psicologia e Ciências da Educação, para poder transmitir tudo aos demais’. (pp. 85-86)

O segundo luto refere-se ao desligamento dos pais da infância. Sobre esse luto, Levenfus (1997) afirma que estes, antes vistos como objetos idealizados e onipotentes, passam, na adolescência dos filhos, por um processo de desidealização. Se, durante a infância, o sujeito os tinha como heróis e únicos modelos ideais a serem seguidos, com a irrupção da adolescência, os mesmos são deslocados dessa posição. O adolescente confronta-se, no real, com figuras parentais limitadas, também marcadas pela castração.

Alberti (2010), ressaltando a importância dos pais para o adolescente, aponta que estes, mesmo se colocando, por vezes, como impotentes para responder às questões da adolescência, ainda são suportes imprescindíveis ao jovem, no exercício de suas escolhas, por constituírem suas referências primárias.

A autora, tratando daquilo que pode falhar no processo de elaboração dos lutos relacionados com o desligamento dos pais da infância, também afirma que as faltas nos pais precisam ser elaboradas pelo filho adolescente, pois é essa elaboração que permitirá o sustento dos novos caminhos a serem construídos por ele, tanto no plano afetivo quanto profissional. Segundo ela, quando isso não acontece, o adolescente identifica-se com o que falha nas figuras parentais, perdendo o contato consigo mesmo, deprimindo-se e expressando, como resposta, uma atitude "de não querer saber" do seu próprio desejo.

Identificar-se com a falta dos pais, no plano da escolha profissional, pode, portanto, levar o adolescente a escolher a partir do desejo de um deles, recaindo tal escolha naquilo que o pai ou a mãe não conseguiu escolher e que escolheria para si se pudesse fazê-lo.

A escolha com base na fixação ao desejo do Outro pode estar relacionada, conforme vimos com Lacan (1998), à relação especular da criança com o Outro materno, vivenciada no estádio do espelho, na qual se dá um assujeitamento desta ao desejo da mãe por querer ocupar o lugar do objeto (o falo) que a ela supõe faltar.

$\mathrm{Na}$ adolescência, o sujeito, confrontado com as escolhas de sua vida (amorosas e/ou profissionais), novamente pode se ver colocado entre a posição de ser o falo materno (eu ideal) e a posição de sujeito desejante (ideal do eu). 
É o caso, por exemplo, de Clarice ${ }^{6}$, a filha mais nova de um casal, cuja mãe desejava muito ter se formado em Medicina. Como isso não aconteceu, ela esperava que uma de suas filhas realizasse o seu sonho. Como a filha mais velha não o fez, cabia à caçula a missão de fazê-lo. No seu primeiro vestibular, identificada com a falta da mãe, ela optou por Medicina, mas não obteve aprovação. Isso the deu a oportunidade de buscar ajuda para repensar a sua escolha e refazê-la, podendo, assim, sair da posição de assujeitada ao desejo da mãe para a posição de sujeito desejante.

Ainda sobre essa operação de desligamento dos pais, tão necessária ao adolescente para que suas escolhas tenham como referência seus próprios desejos, Backes (2011) pontua a importância das pequenas e grandes separações que muitos adolescentes acabam por fazer, como, por exemplo, as viagens para intercâmbio estudantil, dentro ou fora do país, e a saída da casa dos pais para estudar em outra cidade ou para morar com amigos, que cumprem, na maioria das vezes, a função de promover esse corte.

É o caso do adolescente Carlos, que se dividia na sua decisão entre ser médico ou seguir outras carreiras ligadas ao meio-ambiente (Geologia/Engenharia ambiental). A dúvida surgiu após o intercâmbio de 01 ano feito no exterior, o qual possibilitou um afastamento do Outro parental e o questionamento de um significante profissional (ser médico) que se repetia por duas gerações na sua família. Ao trazer suas dúvidas e falar de seus desejos, Carlos pode, por fim, reconstruir sua história pessoal, ressituando o seu lugar no mito familiar, e fazer sua escolha não mais assujeitado a uma única determinação, a do Outro parental, mas a partir das suas identificações com os vários outros significativos que também cruzaram o seu caminho: professores, tio, primo, pessoas com quem conviveu durante o tempo do intercâmbio, etc.

Backes (2011), a partir de uma perspectiva lacaniana, assinala que o sujeito se produz a partir da sua fala, sendo somente pela apropriação desta que ele consegue tomar a palavra em nome próprio e deixar de ser objeto do desejo do Outro. Esse processo, refeito na adolescência sob a forma de reconstituição do recalque originário e da ratificação da instância paterna, só se torna possível quando o sujeito produz uma distância necessária da posição de objeto do Outro originário e/ou paterno. As dificuldades na reconstituição dessas duas operações, na adolescência, se apresentam sempre que o adolescente precisa "tomar para si a palavra e passar da posição de objeto a sujeito" (p. 95) e se traduzem na insistência dos objetos primordiais e/ou na fixação destes nas suas escolhas.

Um terceiro luto a ser feito pelo adolescente diz respeito às transformações corporais impostas pelo real pubertário. Conforme vimos, o adolescente, além de precisar elaborar o luto pelo corpo infantil, modificado pela entrada na puberdade, também se defronta com o luto pelo corpo adolescente, que vai sendo perdido à medida que ele vai se tornando adulto. Nesse sentido, as queixas, ligadas ao fato de o corpo infantil não ter se transformado naquilo que idealizou, irão requerer um trabalho psíquico para que o sujeito possa suportar o abalo que isso representa no seu narcisismo.

No que se refere à escolha profissional, tal fato, segundo Bohoslavsky (1993), possibilita o surgimento de "fantasias de eterna juventude" (p. 86), as quais podem estar relacionadas à escolha de cursos de graduação nos quais subjaz o desejo de: corrigir e/ou curar o próprio corpo, trabalhando sobre o corpo dos outros (Medicina, Fisioterapia, Educação Física, etc.), ou mesmo de nutrir e/ou melhorar o funcionamento deste (Nutrição, Farmácia, etc.).

Ainda sobre esse luto, Levenfus (1997) aponta que é muito frequente os jovens se queixarem de não possuir o corpo adequado para o exercício de determinada profissão. Tais queixas quase sempre expressam a dificuldade de alguns deles em elaborar suas impossibilidades e/ou limitações, isto é, sua própria castração, frente às suas possibilidades de escolha. Tal aspecto pode ser ilustrado por depoimentos do tipo: "Se eu fosse mais alto e encorpado poderia exercer a carreira de bombeiro" (Costa, 2007, p. 96) ou "Se fosse mais alta poderia ser manequim" (Levenfus, 1997, p. 167).

O quarto luto diz respeito às outras identificações profissionais que o adolescente necessita abrir mão para poder optar por uma só profissão. Sobre ele, Levenfus (1997) ressalta que alguns jovens relutam em se desprender das suas outras possibilidades de escolha, principalmente aqueles que possuem um elevado nível de aptidões e um leque de interesses variados. A relutância em separar-se das partes de si que se identificam com esses objetos, leva esses jovens a permanecerem na dúvida entre duas ou mais profissões ou então fazer escolhas nas quais se observa a dissociação entre uma profissão para trabalhar e outra para servir de hobby.

É o caso de Mário, que se dividia entre o curso de Matemática e a carreira de jogador profissional de ping-pong. Somente quando conseguiu trabalhar a sua impossibilidade de seguir duas carreiras, que se situavam em campos distintos, e também se dar conta de que não era bom o suficiente para se tornar um profissional do referido esporte é que ele pode, enfim, escolher ser um profissional na área de Matemática e um amador na área esportiva.

$\mathrm{O}$ quinto luto se refere à perda da condição adolescente frente à assunção dos compromissos e responsabilidades próprios da vida adulta, os quais o adolescente é convocado a assumir na medida em que vai adentrando no mundo adulto. A escolha da profissão entra nesse rol lhe demandando uma capacidade de decisão que até então não exercitara com suficiente frequência e seriedade. Daí o temor de enganar-se e de vir a se arrepender por ter feito uma escolha que julga ser definitiva e também definidora de vários aspectos de sua vida.

6 Todos os nomes usados nesse texto são fictícios. 
De acordo com Levenfus (1997), a dificuldade em fazer o luto de sua condição adolescente pode também se manifestar na forma como o jovem lida com a questão do tempo. Alguns lidam com o tempo aceitando seu próprio crescimento; outros, negando-o (oferecendo resistência às mudanças ou 'permanecendo criança'). Há também os que o aceleram de forma onipotente e os que buscam profissões com representações infantis para poder amenizar o sentimento de perda.

Para Alberti (2010), o trabalho de elaboração de todos esses processos psíquicos próprios da adolescência, que Freud nomeou como elaboração simbólica da castração e Lacan como elaboração da falta no Outro, é de fundamental importância no acesso do adolescente ao seu desejo. Em suas palavras:

Para aceder ao desejo é necessário o reconhecimento da castração da qual, aliás, o desejo se alimenta! . . Poder encarar o desamparo, as impossibilidades, submeter-se à castração simbólica é o longo trabalho de elaboração da falta no Outro que diz respeito à adolescência (Alberti, 2010, p. 16)

Ainda segundo a autora, aceder ao próprio desejo e fazer suas próprias escolhas requer, do adolescente, coragem:

É preciso coragem para escolher! Porque cada escolha, assim assumida como sendo de sua própria responsabilidade, rompe necessariamente com desígnios e ditames. Teoricamente falando, se todo sujeito é alienado ao Outro - ou seja, todo desejo é, por definição, desejo do Outro -, a escolha se faz na vertente inversa, a da separação do Outro, sempre cortando e fazendo recortes nos desígnios e ditames em função do fato de que quando há escolha nem tudo é possível (Alberti, 2010, pp. 41-42).

\section{Considerações Finais}

O percurso realizado em torno dos autores estudados levou-nos à conclusão de que, nas escolhas profissionais, estão implicados processos psíquicos diversos, que tiveram seu início no tempo de constituição do eu e do aparato psíquico e atingiram sua culminância na vivência edípica. Tais processos, atualizados na adolescência a partir de uma repetição significante daqueles vividos na infância, apontam para uma forma de funcionamento psíquico estruturada no sujeito a partir da sua relação ao Outro, originário e parental, cujos traços mnésicos deixados irão sobredeterminar as suas relações com os objetos substitutos e orientar as suas escolhas nos vários campos de sua vida, inclusive o profissional.

Os problemas envolvidos na saída do adolescente de suas relações e identificações primordiais parecem justificar, no caso dos adolescentes apontados no nosso trabalho, e poderíamos também dizer de vários outros, parte das dificuldades desses em fazer suas escolhas no campo profissional.

Diante disso, podemos afirmar, a partir de Lacan, que a função paterna e a operação metafórica que ela viabiliza, de instauração do significante Nome-do-Pai, é de crucial importância em ambos os tempos da vivência edípica, principalmente por promover a separação do sujeito de sua alienação ao Outro materno, na infância, e a sua separação do Outro parental, na adolescência. É, pois, a elaboração simbólica dessa separação dos pais imaginarizados e idealizados e a sua consequente incorporação, através das identificações, bem como a elaboração dos lutos relativos às perdas e renúncias relacionadas às mudanças corporais e aos demais objetos infantis (amigos, professores, projetos profissionais, etc.) que irão permitir ao adolescente abrir-se ao Outro social e reorientar o seu desejo para novas escolhas.

Conforme vimos, no adolescente, a reinscrição do Nome-do-Pai, além de promover a elaboração de todos os processos psíquicos nos quais as suas identificações estão implicadas, sedimenta o ideal do eu como instância que irá assumir o papel de orientador das suas escolhas e projetos de vida.

Diante disso, podemos dizer que as escolhas e projetos profissionais do adolescente passam necessariamente pela construção das instâncias ideais, principalmente o ideal do eu, e não pode prescindir da existência dos modelos de identificação buscados no Outro parental e/ou social. É possível afirmar ainda que a profissão escolhida conflui em si certo número dos traços introjetados pelo adolescente nas diversas identificações processadas na sua história de vida. Essa, de certo modo, diz da forma singular como ele elaborou sua castração e suas identificações e de como conseguiu lidar com as dimensões ambivalentes do seu desejo edípico.

À guisa de conclusão, podemos, por fim, dizer que a dimensão do desejo e do inconsciente sempre estarão presentes nas questões relacionadas às escolhas do sujeito, inclusive às relativas ao campo profissional; daí a importância de construirmos uma escuta das dificuldades aí surgidas, atenta, sobretudo, aos vários determinantes aos quais o sujeito está submetido, na sua história de vida, e às respostas singulares que cada um apresenta frente aos mesmos. É, pois, esse olhar que o estudo da temática referente à escolha profissional na adolescência a partir do referencial psicanalítico pode oferecer. 


\section{Referências}

Alberti, S. (2010). O adolescente e o outro (Coleção Passo a Passo). Rio de Janeiro: Zahar.

Ariès, P. (1981). História social da criança e da família (2a ed.). Rio de Janeiro: LTC.

Backes, C. (2011). O que consome o adolescente? (Tese de Doutorado, Programa de Pós-Graduação em Educação, Universidade Federal do Rio Grande do Sul).

Bohoslavsky, R. (1993). Orientação vocacional: A estratégia clínica (9a ed.). São Paulo: Martins Fontes.

Calligaris, C. (2000). A adolescência. São Paulo: Publifolha.

Costa, N. G. B. (2007). Adolescência e escolha profissional: A escuta de um impasse (Dissertação de Mestrado, Programa de Pós-Graduação em Psicologia Clínica e Social, Universidade Federal do Pará).

Coutinho, L. G. (2009). Adolescência, cultura contemporânea e educação. Revista estilos da clínica, 14(27), 134-149.

Dantas, N. M. (2002). Adolescência e Psicanálise: Uma possibilidade teórica (Dissertação de Mestrado, Programa de Mestrado em Psicologia Clínica, Universidade Católica de Pernambuco).

Freud, S. (1987a). Três ensaios sobre a Teoria da Sexualidade. In Edição Standard Brasileira das Obras Completas de Sigmund Freud (Vol. 7, pp. 119-231). Rio de Janeiro: Imago. (Originalmente publicado em 1905).

Freud, S. (1987b). Conferência XXI: O desenvolvimento da libido e as organizações sexuais. In Edição Standard Brasileira das Obras Completas de Sigmund Freud (Vol. 16, pp. 375-395). Rio de Janeiro: Imago. (Originalmente publicado em 1916-1917).

Freud, S. (1987c). Psicologia de grupo e análise do ego. In Edição Standard Brasileira das Obras Completas de Sigmund Freud (Vol. 18, pp. 89-179). Rio de Janeiro: Imago. (Originalmente publicado em 1921).

Freud, S. (1987d). O mal-estar na civilização. In Edição Standard Brasileira das Obras Completas de Sigmund Freud (Vol. 21, pp. 81-178). Rio de Janeiro: Imago. (Originalmente publicado em 1930/[1929]).

Freud, S. (1987e). Moisés e o monoteísmo: Três ensaios. In Edição Standard Brasileira das Obras Completas de Sigmund Freud (Vol. 23, pp. 13-161). Rio de Janeiro: Imago. (Originalmente publicado em 1939/[1934-1938]).

Lacan, J. (1998). O estádio do espelho como formador da função do eu tal como nos é revelada na experiência psicanalítica. In J. Lacan, Escritos (pp. 96-103). Rio de Janeiro, Jorge Zahar. (Obra original publicada em 1966).

Lacan, J. (1999). O seminário, livro 5: As formações do inconsciente (1957-1958). Rio de Janeiro: Jorge Zahar.

Levenfus, R. S. (1997). Os lutos da escolha profissional. In R. S. Levenfus (Org.), Psicodinâmica da escolha profissional (pp. 163-173). Porto alegre: Artes Médicas.

Lima, C. P. (2012). O declínio do mestre e sua relação com o saber na adolescência. In R. Gurski, M. D. Rosa, \& M. C. Poli (Orgs.), Debates sobre a adolescência contemporânea e o laço social (pp. 161-170). Curitiba: Juruá.

Mannoni, M. (1996). Apresentação do texto de Octave Mannoni. In A. I. Corrêa (Org.), Mais tarde... é agora!: Ensaios sobre a adolescência (pp. 13-19). Salvador: Ágalma.

Poli, M. C., \& Becker, A. L. (2004). Adolescência: uma abordagem na psicanálise lacaniana. In M. M. K. Macedo (Org.). Adolescência e Psicanálise: Intersecções possíveis (pp. 133-153). Porto Alegre: EDIPUCRS. 
Rassial, J. (1997). A passagem adolescente: Da família ao laço social. Porto Alegre: Artes e Ofícios.

Rodulfo, R. (1990). O brincar e o significante. Porto Alegre: Artes Médicas.

Roudinesco, E., \& Plon, M. (1998). Dicionário de psicanálise. Rio de Janeiro: Jorge Zahar.

Torres, M. L. C. (1998). O processo clínico de orientação profissional. Rev. ABOP, 2, 29-37.

Torres, M. L. C. (2001). Orientação profissional clínica: Uma interlocução com conceitos psicanaliticos. Belo Horizonte: Autêntica.

Viola, D. T. D., \& Vorcaro, A. M. R. (2015). O problema do saber na adolescência e o real da puberdade. Revista Psicologia USP, 26(1), 62-70.

\section{Endereço para correspondência}

Juvaneide Régia Costa

Email: juvaneide@hotmail.com

Cynthia Pereira de Medeiros

Email: cynthiamedeiros@yahoo.com

Cynara Teixeira Ribeiro

Email: cynara_ribeiro@yahoo.com.br 